\title{
PRE STACK DEPTH MIGRATION UNTUK KOREKSI EFEK PULL UP DENGAN MENGGUNAKAN METODE HORIZON BASED DEPTH TOMOGRAPHY PADA LAPANGAN 'A1 DAN A2'
}

\author{
Atikah Azzahra $^{1 *}$, Bagus S. Mulyatno', Bambang Mujihardi ${ }^{2}$ \\ ${ }^{1)}$ Jurusan Teknik Geofisika, Universitas Lampung \\ Jl. Prof. Dr. SumantriBrojonegoro No.1 BandarLampung35145 \\ ${ }^{2)}$ PT Pertamina Upstream Technology Center \\ Jl. Medan Merdeka Tim. No.6, Jakarta Pusat 10110 \\ Jurusan Teknik Geofisika, FT UNILA \\ e-mail: *1 atikahazzahra1996@gmail.com
}

\begin{abstract}
ABSTRAK
Pada kasus pengolahan data seismik dengan litologi batu pasir seperti shale dan karbonat sering sekali didapatkan hasil pengolahan data yang memiliki efek pull up terutama pada hasil migrasi domain waktu. Pre stack depth migration merupakan pengolahan yang berdasarkan focusing amplitudo sesuai dengan kedalaman yang sebenarnya dengan menggunakan input kecepatan interval. Migrasi yang dilakukan menggunakan algoritma kirchhoff pre stack depth migration. Pre stack depth migration yang dilakukan dilengkapi dengan pemodelan kecepata berupa metode horizon based depth tomography. Metode ini menggunakan koreksi residual moveout yang diterapkan sepanjang garis hasil picking interpretasi horizon. Penelitian ini menggunakan dua data lapangan yaitu lapangan A1 dan A2. Lapangan A1 memiliki karakteristik batuan karbonat yang menghasilkan pull up berbentuk mirip dengan lapisan karbonat. Lapangan A2 memiliki efek pull up yang tidak terlalu jelas namun mengalami build up karena lapisan diatasnya. Tahapan - tahapan yang dilakukan dimulai dari pengolahan pre stack time migration berupa picking kecepatan, menghasilkan kecepatan rms dan melakukan migrasi domain time. Proses pre stack depth migration diawali dengan transformasi kecepatan dengan persamaan transformasi dix untuk menghasilkan kecepatan interval, melakukan migrasi Pre stack depth migration, melakukan interpretasi horizon dan melakukan pemodelan kecepatan dengan metode horizon based depth tomography. Iterasi dilakukan sebanyak 4 kali dan menghasilkan section final pre stack depth migration yang telah terkoreksi oleh efek pull up.
\end{abstract}

\begin{abstract}
In the case of seismic data processing with sandstone lithology such as shale and carbonate often get the result of data processing which have pull up effect especially on the time domain migration result. Pre stack depth migration is a processing based on focusing the amplitude according to the actual depth by using the input interval velocity. Migration is performed using kirchhoff pre stack depth migration algorithm. Pre stack depth migration is done with modeling of horizontal based depth tomography method. This method uses residual moveout correction applied along the horizon-picking line. This research uses two field data that is A1 and A2 Field. A1field has characteristics of carbonate rock that produce pull up shaped similar to carbonate layer. A2 field has a pull-up effect that is not very clear but has build up because of the layer above it. Stages performed starting from the processing of pre stack time migration in the form of velocity picking, generate rms velocity and migration time domain. The pre stack depth migration process begins with a velocity transformation with the dix transformation equation to generate interval velocity, migrate Pre stack depth migration, perform horizon interpretations and perform velocity modeling using the horizon based depth tomography method. The iteration is done 4 times and resulted in the final section of pre stack depth migration which has been corrected by pull up effect.
\end{abstract}

Keywords-Pre stack depth migration, pull-up effect, horizon based depth tomography 


\section{PENDAHULUAN}

\subsection{Latar Belakang}

Keberadaan metode seismik adalah metode geofisika yang terbaik digunakan dalam dunia eksplorasi hidrokarbon. Metode seismik refleksi memberikan kontribusi besar dalam kegiatan eksplorasi seismik. Metode Seismik merupakan metode yang sangat baik untuk pencitraan bawah permukaan. Hal ini disebabkan metode seismik mempunyai ketepatan serta resolusi yang tinggi dalam memodelkan struktur geologi dibawah permukaan bumi.

Untuk mencitrakan bawah permukaan dengan akurat dan mendapatkan gambaran bawah struktur permukaan,pengolahan data seismik tersebut dilakukan. Karena hasil data akuisisi di lapangan masih banyak dipengaruhi oleh noise dan belum menggambarkan struktur geologi bawah permukaan yang sebenarnya, sehingga perlu dilakukan teknik-teknik pengolahandata seismik yang lebih spesifik. Hasil akhir dari suatu pengolahan data seismik adalah suatu penampang seismik yang telah dilakukan migrasi. Migrasi merupakan tahapan dalam pengolahan data seismik yang bertujuan untuk mengembalikan reflektor miring ke posisi sebenarnya, sehingga meningkatkan resolusi spasial hasil dari gambaran seismik bawah permukaan (Yilmaz, 2000).

Pada kondisi litologi yang beragam dan variasi kecepatan lateral yang cukup kompleks teknik PSTM (Pre Stack Time Migration) atau dengan kata lain migrasi dengan domain waktu tidak memberi solusi. Teknik PSTM hanya dapat mengatasi variasi kecepatan data secara vertikal, oleh karena itu digunakanlah teknik PSDM (Pre Stack Depth Migration). Teknik ini dapat digunakan untuk mengatasi variasi kecepatan secara lateral dan vertikal. Pada kasus tertentu metode PSDM merupakan solusi untuk identifikasi permasalahan untuk litologi yang memiliki efek pull-up

Efek pull up terjadi pada litologi batu pasir akibat perbedaan kecepatan pada shale dan karbonat. Perbedaan kecepatan secara lateral yang cukup besar mengakibatkan terjadinya kesalahan dalam pembuatan model kecepatan, sehingga citra bawah permukaan yang dihasilkan menjadi tidak akurat, oleh karena itu dibutuhkan metode yang lebih efektif dan akurat untuk menyelesaikan permasalahaan Metode Horizon Based Depth Tomography merupakan analisis tomografi untuk perbaikan model kecepatan yang sangat efektif untuk mengoreksi efek pull up pada penampang seismik. Hasil pemodelan ini diharapkan dapat memberikan suatu informasi akurat untuk menghasilkan suatu penampang seismik yang dapat digunakan selanjutnya dalam interpretasi data seismik.

\subsection{Tujuan Penelitian}

Tujuan dari penelitian ini adalah sebagai berikut:

1. Melakukan pemodelan kecepatan Horizon Based Depth Tomography, sehingga dihasilkan penampang seismik yang terkoreksi oleh efek pullup.

2. Menganalisis penampang seismik hasil Pre Stack Depth Migration dalam mencitrakan struktur bawah permukaan yang lebih baik dan akurat.

3.. Membandingkan hasil pengolahan dengan teknik Pre Stack Time Migration dan Pre Stack Depth Migration

\section{TINJAUAN PUSTKA}

\subsection{Geologi Regional}

Cekungan ini terletak di antara Paparan Sunda di Utara, Jalur Perlipatan - 
Bogor di Selatan, daerah Pengangkatan Karimun Jawa di Timur dan Paparan Pulau Seribu di Barat.Cekungan Jawa Barat Utara dipengaruhi oleh sistem block faulting yang berarah Utara - Selatan. Patahan yang berarah Utara - Selatan membagi cekungan menjadi graben atau beberapa sub-basin, yaitu Jatibarang, Pasir Putih, Ciputat, Rangkas Bitung dan beberapa tinggian basement, seperti Arjawinangun, Cilamaya, Pamanukan, Kandanghaur-Waled, Rengasdengklok dan Tangerang.Peta dapat dilihat pada Gambar 1.

Cekungan Barito merupakan cekungan berumur Tersier yang terletak di bagian tenggara Schwaner Shield di daerah Kalimantan Selatan. Cekungan ini dibatasi Pegunungan Meratus pada bagian timur dan pada bagian utaranya berbatasan dengan Cekungan Kutai. Cekungan Barito pada bagian selatan dibatasi Laut Jawa dan bagian barat dibatasi oleh Paparan Sunda (Kusuma dan Nafi, 1986).

Cekungan Barito termasuk didalamnya Meratus Range yang dicirikan dengan endapan berumur Paleogen yang terdiri dari batupasir kuarsa, konglomerat, serpih, batulempung, lapisan batubara dan pada bagian atasnya berupa napal dan batugamping yang telah mengalami perlipatan dan pensesaran secara intensif pada akhir zaman Tersier (Van Bemmelen, 1949). Peta dapat dilihat pada Gambar 2.

\section{TEORI DASAR}

\subsection{Transformasi Dix}

Dix menurunkan persamaan untuk traveltime, dengan mempertimbangkan raypath bending, pada kasus banyak lapisan yang datar. Dix berpendapat bahwa, untuk sudut kecil $\mathrm{V}_{\text {rms }}$ dapat digunakan pada formula moveoutdan memprediksi traveltime untuk beberapa offset $\mathrm{V}_{\text {rms }}$ didefinisikan sebagai:

$$
V_{r m s}=\left[\frac{\sum V_{\text {int }-i_{i} t_{i}}}{\sum t_{i}}\right]^{\frac{1}{2}}
$$

dengan Vint- $i$ adalah kecepatan interval tiap lapisan, $t_{i}$ adalah ketebalan tiap lapisan. Dix juga menurunkan formula untuk kecepatan interval dari traveltime dan $V_{r m s}$, dan sering disebut sebagai persamaan dix:

$V_{\text {int }(A-B)}^{2}=\frac{V_{\text {Tms }}^{\mathrm{z}}(B) \cdot T_{B-V_{\text {rms }}(A)} \cdot T_{A}}{T_{B}-T_{A}}$

dengan $V \operatorname{int}(A B)$ adalah adalah kecepatan interval antara permukaan A dan B, TA adalah normal incidence traveltime untuk permukaan A, TB adalah normal incidence traveltime untuk permukaan $\mathrm{B}$ (Fagin, 1999).

\subsection{Tomografi Refleksi}

Untuk mendapatkan persamaan tomografi dibutuhkan suatu hubungan antara errorTomografi pada migrasi kedalaman adalah sebuah metode untuk menyempurnakan model kecepatan saat migrasi kedalaman yang dilakukan dengan model kecepatan residual moveout. Tomografi menggunakan ukuran ketidak dataran (residual moveout) ini sebagai upaya untuk menemukan model alternatif yang akan meminimalkan kesalahan. Ilustrasi tomografi refleksi sederhana dapat dilihat pada Gambar 3.

Gambar 3 menunjukan model sederhana dengan bawah permukaan dibagi menjadi sembilan sel persegi panjang yang masing - masing memiliki kecepatan konstan berbeda yang menggambarkan prinsip dasar tomografi. Waktu datang untuk raypath $\mathrm{ABC}\left(\mathrm{t}_{\mathrm{ABC}}\right)$ dimana raypath berasal dari $\mathrm{A}$, kemudian terefleksi dari kemiringan lapisan $\mathrm{B}$ dan sampai pada receiver $\mathrm{C}$, dituliskan sebagai: $t_{A B C}=\frac{d_{1}}{v_{1}}+\frac{d_{5}}{v_{5}}+\frac{d_{g}}{v_{g}}+\frac{d_{6}}{v_{6}}+\frac{d_{g}}{v_{g}}$

Tomografi waktu tempuh refleksi berdasarkan perturbasi parameter model awal dengan jumlah yang kecil dan mencocokkan perubahannya dalam waktu tempuh terhadap pengukuran waktu tempuh dari analisis residual moveout pada imagegathers. Kita harus melakukan yang 
terbaik saat model building sehingga hanya tersisa sedikit perbedaan yang akan dibuat terhadap model dengan tomografi. Khususnya, update tomografi dapat diharapkan bekerja melakukan perubahan, yang akan dibuat terhadap parameter model awal, yaitu slowness(s) dan kedalaman $(z)$ pada batas lapisan, yang kecil jika dibandingkan terhadap parameter modelnya. Tomografi waktu tempuh refleksi dalam implementasinya, parameter model akan diperturbasi saat offset-nya tetap.

Perhitungan tomografi dilakukan untuk memperbaiki slowness (kelambatan) dan waktu vertikal ( $t v$ ) pada kecepatan dan batas perlapisan dalam formasi (Kosloff, 1999).

waktu $\delta \tau$ dengan model yang sudah diperbarui $\delta t v$ dan slowness error $\delta s$ (Kosloff dkk, 1996).

$\delta t=\int_{\mathrm{ray}} \delta S_{L} d l+\sum_{\mathrm{i}=1}^{\mathrm{Wwl}-1} \Delta P_{z}^{\mathrm{q}} \delta$

Dimana $\Delta \mathrm{P}_{\mathrm{x}}^{\mathrm{i}}$ adalah perubahan pada slowness vertikal dari sinar antara titiklangsung dibawah dan diatas dengan bidan batas ke-i, $\delta S_{L}$ adalah kesalahan padaslowness, $\delta_{z i}$ adalah kesalahan pada kordinat vertikal

\subsection{Model Horizon Based Tomography}

Model kecepatan awal yang diperoleh dari tranformasi interval velocity digunakan untuk melakukan proses PSDM. Pendekatan layer stripping dalam tranformasi interval velocity seringkali menghasilkan akumulasi errorpada lapisan yang lebih dalam bila pada lapisan di atasnya tidak tepat, sehingga akan menghasilkan errorwaktu tempuh. Untuk itu dilakukan perbaikan (refinning) model secara iteratif yang disebut global tomografi, karena perubahan parameter model kecepatan dan kedalaman dilakukan secara simultan tidak berdasarkan pendekatan layer stripping. Pada studi yang telah dilakukan biasa digunakan horizon based tomography dimana model kecepatan interval dari tranformasi interval velocity dan residual moveout $\mathrm{CRP}$ depth gathersebagai data masukannya.

Model kedalaman diperbaiki secara iteratif dengan memodifikasi interface kedalaman dan kecepatan lapisan untuk membuat gathermenjadi datar. Iluustrsi Horizon Based Tomographydapat dilihat pada Gambar 4.

Menggunakan ray tracing, errordari tiap lapisan digunakan untuk membuat matriks tomografi sepanjang lintasan gelombang. Errordari tiap lapisan diselesaikan secara simultan menggunakan metode least square untuk meminimalisasi kesalahan waktu tempuh yang melewati seluruh model (Mualimin dkk, 2004).

\subsection{Efek pull up}

Konversi data seismik dari domain waktu menjadi domain kedalaman merupakan hal yang sangat penting didalam dunia eksplorasi migas. Pengambilan keputusan untuk program pengeboran didalam domain waktu merupakan hal yang sangat membahayakan. Karena, seringkali interpretasi didalam domain waktu akan menghasilkan penafsiran yang tidak tepat terutama pada zona di bawah kecepatan tinggi seperti sub-salt ataupun sub carbonate. Tidak seperti migrasi dalam kawasan waktu, migrasi dalam kawasan kedalaman mencover perubahan kecepatan secara lateral. Untukflat overburden, perubahan kecepatan secara lateral adalah kecil, lain halnya dengan daerah dengan struktur yang kompleks, (Abdullah, 2009).

Dibawah zona ini, akan diperoleh pull up velocity anomaly atau antiklin semu padahal pada keadaan sesungguhnya hanyalah datar-datar saja atau bahkan sinklin, seperti yang terlihat pada Gambar 5.

Konversi kedalaman adalah cara untuk menghilangkan ambiguitas struktural yang melekat pada domain 
waktu dan untuk menverifikasi stuktur. Ada banyak metode untuk mengubah waktu seismik menjadi kedalaman. Metode konversi waktu menjadi kedalaman dapat dipisahkan menjadi dua kategori besar: konversi waktu-kedalaman langsung, dan pemodelan kecepatan untuk konversi kedalaman (Edward dkk, 2002).

\section{METODE PENELITIAN}

\subsection{Alat dan Bahan}

Adapun alat dan bahan yang digunakan dalam penelitian ini adalah sebagai berikut:

- Perangkat keras meliputi CPU (Central Processing Unit)

- Komputer dengan sistem operasi Linux (read head)

- Aplikasi (software)Paradigm15.5

- Data seismik 2D

\subsection{Pengolahan Data}

\subsubsection{Import Data}

Proses pembacaan data berupa SEG $\mathrm{Y}$ import. Data merupakan data hasil proses pre stack time migration. Maka data yang di input berupa time gather. Pada proses input datadilakukan inputtrace header dengan menyeleksi parameter data dan memasukan kode byte yang terdapat pada general info/ EBCDIC. Byte yang dimasukan akan membaca value data. EBCDIC merupakan informasi yang terdapat pada data gather isinya berupa tipe data, format data, nama line, header info bytes, parameter akuisisi data, rangkaian processing yang telah dilakukan sebelumnya sebagai input ke software seismic 2D GeoDepth Paradigm 15.5.

\subsubsection{Pembacaana Line Pada Base Map}

Proses ini merupakan pembacaan arah koordinat $x$, koordinat $y$, arah line data, CMP data.

\subsubsection{Picking semblance}

Proses ini berupa pemilihan kecepatan dengan metode semblance yang dilakukan pada time gather. Metode semblance menampilkan spektrum kecepatan dalam bentuk kontur warna dan melalui proses picking akan mengakibatkan diterapkanya proses NMO. Proses picking berupa pemilihan kecepatan yang diwakili dengan koherensi warna maksimum. Pada semblance vertical koherensi maksimum ditunjukan dengan warna biru sampai koherensi minimum berwarna merah. Hasil dari proses ini didapatkanya stacking velocitykemudian dihasilkanlah $R M S$ velocity.

\subsubsection{Pre Stack Time Migration}

Migrasi time merupakan migrasi domain waktu dimana kecepatan input berasal dari RMS velocity. Migrasi pada tahap ini menggunakan konsep kecepatan model yang berupa gradient kecepatan secara vertikal. Proses migrasi ini menggunakan algoritma migrasiKirchhoff pre stack time migration curve rays. Tahapan ini merupakan tahapan awal menentukan objek lapisan yang nantinya akan diterapkan koreksi efek pull up, serta menentukan batas antar lapisan yang natinya akan difokuskan untuk proses pemodelan kecepatan.

\subsubsection{Pre Stack Depth Migration}

Kecepatan input proses berasal dari interval velocity. Interval velocity didapatkan dari transformasi kecepatan rms velocity menggunakan persamaan transformasi dix. Migrasi yang dihasilkan 
berasal dari migrasi dengan algoritma kirfchhoff berupa pre stack depth migration Kirchhoff wavefront dan data time gathersebagai masukan.

\subsubsection{Interpretasi Horizon}

Interpretasi horizon diterapkan dengan membuat garis horizon yang didasarkan atas pola reflektor yang kuat sebagai batas antar lapisan pada section initialPSDM. Proses ini juga dinamakan picking along horizon yang dilakukan di sepanjang peak (puncak) traceseismik.

\subsubsection{Pemodelan kecepatan}

Pemodelan menggunakan $V_{\text {int }}$ akan terbentuk dan terlihat pada velocity window berupa model kecepatan hasilinterpretasi selanjutnya, dibentuk model kecepatan baru sebagai input untuk proses tomografiyang terdiri dari model kurva kecepatan.

\subsubsection{Residual Moveout along Horizon}

Analisis ini berupa identifikasi residual moveout yang dibutuhkan agar reflektor pada depth gather menjadi lurus. Pengolahan ini dilakukan berdasarkan time residualyaitu pengukuran moveout yang masih tersisa pada reflektor depth gather setelah diterapkanya NMO atau setelah migrasi.

\subsubsection{Iterative PSDM}

Iterrative akan dilakukan hingga
dihasilkan final depth migrated
gatheryaitupenampang seismik dengan
citra terbaik, sesuai dengan struktur
geologi sebenarnya dan terkoreksi dengan
tepat.

Iterrative akan dilakukan hingga dihasilkan final depth migrated gatheryaitupenampang seismik dengan citra terbaik, sesuai dengan struktur tepat.

\section{HASIL DAN PEMBAHASAN}

\subsection{Pengolahan Seismik PSTM}

Pengolahan ini diawali dengan import data seismik seg-y dengan memasukan parameter data pada trace header. Proses ini berfungsi untuk memberikan informasi lapangan pada data berdasarkan informasi pada EBCDIC yaitu informasi berdasarkan pengolahan data yang telah dilakukan sebelumnya sehingga didapatkan gather data. Gather ini belum terkoreksi NMO karena data yang diberikan tidak memiliki kecepatan RMS. Adapun gather data Lapangan terdapat padaGambar 6. (a) dan (b).

Lintasan pada lapangan A1 memiliki lintasan dengan arah north west-south east dan lapangan A2 memiliki lintasan yang berarah north east-south west. Kemudian, dilakukanlah proses picking semblance dengan menerapkan proses NMO.

Pada lintasan A1 picking semblance dilakukan pada gather time dan melakukan picking pada sprektrum dengan kecepatan yang tinggi yaitu kisaran time $1 \mathrm{~s}$ sampai 2.4 s sedangkan, pada lapangan A2 picking semblance dilakukan pada kisaran time $0.6 \mathrm{~s}$ sampai $1 \mathrm{~s}$. Pada semblance velocity terdapat garis kecepatan stacking yang mengikuti pola spektrum dengan asumsi semakin dalam maka kecepatan akan semakin besar. Pada time tersebut koreksi NMO diterapkan mengenai reflektor sehingga gather menjadi datar serta dilakukanya muting pada gather untuk membantu memperjelas spektrum warna pada semblance yang dihasilkan dan mempertegas reflektor pada gather time.Picking yang digunakan menggunakan kecepatan stacking yang menggambarkan kecepatan ketika melakukan penerapan NMO. Koreksi NMO dilakukan setiap 30 CMP dari total 4.028 CMP pada lapangan A1 dan setiap 15 CMP dari total 1.392 CMP.

Penampang kecepatan RMS (root mean square) secara horizontal menunjukan pertambahan nilai CMP dan secara vertikal 
menunjukan pertambahan nilai time. Variasi kecepatan menandakan keberadaan struktur yang kompleks maka RMS menggambarkan letak keberadaan struktur pada data seismik. Pada RMS velocity lapangan A1 variasi kecepatan sampai pada time $4000 \mathrm{~m} / \mathrm{s}$ sedangkan pada lapangan A2 variasi kecepatan sampai pada time $2000 \mathrm{~m} / \mathrm{s}$. Kecepatan RMS ini berasal dari kecepatan stacking yang diubah menjadi kecepatan rata-rata dari seluruh lapisan secara horizontal. RMS velocity mengasumsikan bahwa dibawah permukaan memiliki variasi kecepatan yang dianggap sama secara vertikal. Pengolahan selanjutnya yaitu PSTM (pre stack time migration) yang dilakukan menggunakan input kecepatan RMS. PSTM merupakan migrasi yang berdasarkan domain waktu. PSTM yang dilakukan menggunakan aperture 1951.3 m pada lapangan A1 yaitu pada Gambar 7aperture 679.4 m pada lapangan A2 pada Gambar 8dan menggunakan metode kirchhoff pre stack time migration.

\subsection{Pengolahan seismik PSDM}

Pengolahan pre stack depth migration dibutuhkan input kecepatan interval untuk melakukan migrasi. Interval velocity yang digunakan didapatkan dari transformasi kecepatan RMS. Transformasi kecepatan yang digunakan menggunakan persamaan transformasi dix (persamaan 1.2).

Kecepatan interval yang didapat digunakan untuk mengolah prosesPSDM dengan mengunakan data CDP (Common Depth Point) sebagai masukan yang menggunakan migrasi algoritma Kirchhoff. lebar aperture untuk mendapatkan hasil migrasi PSDM pertama atau sering disebut initial PSDM.

Berdasarkan pemilihan aperture penulis memilih aperture $1951.3 \mathrm{~m}$ yang memiliki nilai setengah dari far offset yaitu 3946 m berdasarkan asumsi bahwa pada section migrasi tersebut reflektor terlihat lebih jelas dan tidak terputus.
Pada data A2 lapangan ini memiliki far offset $1965 \mathrm{~m}$. Berdasarkan hasil tersebut ditentukanlah aperture yang terpilih sebesar 697.4 m. Pemilihan ini berdasarkan percobaan karena pada dasarnya reflektor kuat dan tebal yang dihasilkan dari nilai aperture harus melalui tahap pemilihan parameter.

\subsection{Perbaikan model kecepatan metode Horizon Based Depth Tomography}

Langkah awal pemodelan kecepatan dimulai dari tahap interpretasi horizon yaitu melakukan picking horizon berdasarkan kenampakan amplitude yang kuat karena merupakan batas antar lapisan. Interpretasi Horizon Lapangan A1 ditunjukan pada Gambar 9 dan Interpretasi Horizon Lapangan A2 pada Gambar 10.

Picking dilakukan pada peak yaitu yang berwarna hitam karena memiliki amplitude yang kuat dan memiliki pola reflektor yang menerus. Adapun untuk lapangan A1 memiliki interpretasi horizon sebanyak 8 horizon sedangkan untuk lapangan A2 memiliki 6 horizon. Garis horizon ini mewakili kecepatan tiap lapisan diatasnya sehingga didapatkan perbedaan kecepatan lapisan secara horizontal. Garis horizon diberi perbedaan warna untuk memudahkan proses pengolahan dan interpretasi. Pada dua garis terakhir horizon merupakan pemodelan yang harus dibuat agar software menampilkan kecepatan yang benar. Pada lapisan horizon paling akhir hal ini menjadi cara khusus yang dilakukan dalam pengolahan agar tidak terjadi kesalahan pembacaan kecepatan software paradigm 15.5.

Kecepatan hasil interpretasi horizon merupakan acuan kecepatan untuk pemodelan tomografi yang didasari oleh metode horizon based depth tomography. Membuat garis horizon interpretasi harus mengenai reflektor secara tepat dan membentuk perlapisan agar didapatkan 
hasil pemodelan kecepatan yang sebenarnya. Nilai kecepatan ini berasal dari nilai kecepatan interval. Warna garis pada kurva disesuaikan denga $\mathrm{n}$ warna garis pada interpretasi horizon. Garis horizon ini selanjutnya dibaca oleh sistem untuk menampilkan nilai kecepatan pada tiap lapisan horizon dengan berbentuk kurva secara horizontal pada menu vel view.

Analisis selanjutnya yaitu pada residual moveout untuk memperbaiki gather yang belum terkoreksi sepenuhnya oleh NMO agar dapat kembali kepada posisis zero depth error. Analisis ini didasarkan pengukuran moveout yang masih tersisa pada gather. Proses residual moveoutdengan acuan 6 tampilan untuk kecepatan untuk, (a) merupakan kecepatan tomografi disertai interpretasi horizonya dari tampilan ini kita dapat mengetahui letak residual yang sedang dikoreksi pada garis CMP data, (b) merupakan kurva antara residual depth move out dengan kurva interval velocity secara vertikal dengan garis horizontal berwarna menunjukan horizon untuk letak pada kecepatan intervalnya, (c) depth gather untuk melihat secara keseluruhan dari gather dan letak horizon pada reflektor, (d) Semblance residual moveout, menunjukan model kecepatan residual depth moveout dengan spektrum warna dimana sumbu vertikal menunjukan besar moveoutnya dan horizontal menunjukan letak CMP, (e) interactive picking menunjukan besar kecepatan yang dilihat dari gambar berwarna biru / sumbu horizontal dan nilai residual move out yang ada secara vertikal dan (f) QC depth gather, menunjukan perubahan gather oleh residual yang diterapkan apakah sudah flat.

\subsection{Analisis pemodelan kecepatan}

Pemodelan kecepatan tomografi dilakukan dengan beberapa iterasi adapun iterasi yang dilakukan mencapai 4 kali.
Update kecepatan akan menghasilkan model baru dalam kecepatan tomografi adapun model kecepatan berasal dari hasil analisis yang dilakukan berulang - ulang dengan repicking horizon pada section, melakukan residual moveout yang berulang sampai mendapatkan depth migrated gather yang flat pada setiap horizon dan melakukan migrasi tomografi.

Pemodelan kecepatan berhenti pada iterasi ke-4 karena tomografi mendapatkan hasil gather yang flat. Pada pengolahan PSTM dengan domain time kecepatan input berasal dari kecepatan RMS. Pada pengolahan PSDM dengan domain depth menggunakan kecepatan interval dengan persamaan transformasi dix. Perbandingan model kecepatan RMS kecepatan Initial Tomografi dan kecepatan final tomografi lapangan A1 terdapat pada Gambar 11.Perbandingan model kecepatan RMS kecepatan Initial Tomografi dan kecepatan final tomografi lapangan A2 terdapat pada Gambar 12.Hubungan dari anomaly kecepatan dan penampang seismik ditunjukan pada gambar Gambar 13dan Gambar 14.

Pada lapangan A1 terdapat kontras kecepatan dengan interval $1500-4000$ $\mathrm{m} / \mathrm{s}$ pada penampangan yang diindikasi tersusun atas batuan karbonat sedangkan pada kecepatan yang lebih rendah disekitarnya tersusun atas batuan shale.Sehingga menjadi kemungkinan besar untuk wilayah yang memiliki kontras kecepatan tersebut memiliki perubahan struktur pada penampang seismik.

Penyebab utama efek pull up pada lapangan A1 terlihat berdasarkan penampakan kontras kecepatan seperti yang terdapat pada garis lingkar berwarna hitam. Berdasarkan kontras kecepatan tersebut (hijau ke merah) mengakibatkan daerah shale yang terdapat dibawah zona itu menghasilkan efek pull up. Maka zona harus mengalami tahap koreksi. dibawah wilayah tersebut menjadi fokus tomografi lapangan A1 untuk dikembalikan pada posisi reflektor yang sebenarnya. 
Pemodelan kecepatan didasari atas hasil interpretasi sehingga kecepatan Horizon Based Depth Tomography menghasilkan bentuk blocky.

Pada lapangan A2 terdapat 3 fokus efek pull up yang terlihat pada PSTM seismik, kemudian dibuktikan dengan kontras kecepatan model tomografiyang ditandai dengan lingkaran berwarna hitam. Kontras kecepatan mengindikasikan terdapat anomaly berupa batuan karbonat yang dikelilingi oleh shale.

Pada domain waktu kecepatan digambarkan secara konstan yang mengartikan semakin dalam maka akan semakin cepat namun pada kondisi geologi sebenarnya dapat terjadi kemungkinan lain yaitu kecepatan yang lebih tinggi berada diatas lapisan yang lebih rendah yang disebabkan oleh kondisi fisis berupa tekanan, suhu, porositas dan lainnya, serta dapat diakibatkan efek-efek geologi seperti fault ( patahan), saltdome, diapir, reef dan sebagainya Pada lapangan A2 terdapat kontras nilai kecepatan dengan warna hijau - merah berkisar dengan interval kecepatan 2800 - $4600 \mathrm{~m} / \mathrm{s}$ yang diindikasi terdapat susunan batuan karbonat sedangkan pada kecepatan rendah disekitarnya tersusun atas batuan shale.

\subsection{Koreksi Efek pull up}

Hasil penampang PSTM dari A1 memperlihatkan reflektor dengan kemenerusan yang sudah terlihat jelas namun, hasil dari section PSDM memiliki citra yang lebih baik. Perbandingan hasil PSTM dan PSDM lapangan A1 terdapat pada Gambar 15.

Hal ini disebabkan karena migrasi domain waktu memiliki asumsi hyperbolic moveout koreksi kecepatan yang dilakukan kurang tepat dan pada hasil section PSDM efek pull up berhasil terkoreksi. Pada section PSTM sering terjadinya gagal positioning sehingga pada daerah - daerah struktur tertentu menjadi tidak tegas. Variasi kecepatan lateral juga sangatlah berpengaruh menyebabkan pencitraan pada PSTM menghasilkan kesalahan dalam mendeskripsika geometri kurva difraksi. Kurva difraksi berada pada posisi tegak lurus terhadap kedatangan gelombang pada permukaan. Posisi tersebut merupakan lintasan terpendek antara permukaan dengan titik difraktor sehingga teridentifikasi sebagai kurva difraksi sehingga menghasilkan ketidaktepatan posisi (mispositioning) event.

Lapangan A2 juga memiliki hasil yang sama pada PSDM citra yang dihasilkan terlihat lebih menerus dibandingkan penampang PSTM. Pengolahan PSDM tidak berdasarkan hyperbolic moveout melainkan dilakukan dengan focusing untuk tiap titik amplitude pada setiap offset agar posisinya sesuai dengan kedalaman yang sebenarnya. Perbandingan hasil PSTM dan PSDM lapangan A2 terdapat pada Gambar 16.

Pada lapangan A1 efek pull up terlihat dalam lingkaran berwarna merah. Penampang PSTM lapangan A1 memiliki efek pull up pada time 1500 - $2500 \mathrm{~s}$ pada CMP 2730 dan CMP 3130. Reflektor yang berada dibawah reflektor yang memiliki kontras kecepatan yang tinggi seperti karbonat, reflektor pada lingkaran merah tidak tercitrakan seperti keadaan yang sebenarnya melainkan berbentuk seperti reflektor diatasnya/mengalami build up. Namun, pada PSDM tomography final reflektor sudah kembali kepada keadaan yang sebenarnya dan memperjelas struktur padapenampang seismik.

Pada hasil dari lapangan A2 pada time 450 dan 650 CMP 2250, time $600 \mathrm{CMP}$ 3050 , terdapat 3 buah pull up yang diduga disebabkan oleh formasi batuan karbonat diatasnya. Pada hasil PSDM tomography final lapangan A2 reflektor sudah beradapada posisi sebenarnya. Efek pull up pada lapangan $A 1$ dan $A 2$ pada penelitian ini berhasil terkoreksi. Sehingga tujuan dari penelitian ini sudah tercapai. 


\section{KESIMPULAN DAN SARAN}

\subsection{Kesimpulan}

Berdasarkan hasil penelitian tersebut dapat disimpulkan sebagai berikut:

1. Efek pull upyang terdapat pada lapangan A1 terdapat dua objek yang disebabkan oleh susunan batuan karbonat efek pull up mengikuti bentuk dari batuan karbonat pada lapisan shale. Pada lapangan A2 terdapat tiga objek indikasi pull up yang disebabkan oleh lapisan batuan karbonat yang dikelilingi oleh shale.

2. Penampang PSTMlapangan A1 memiliki efek pull up pada time 1500 - $2500 s$ pada CMP 2730 dan CMP 3130 dan A2 pada time 450 dan 650 CMP 2250, time 600 CMP 3050.Efek pull up tersebut dapat terkoreksi melalui proses PSDMtomography.

3. Pengolahan PSDM mampu menghasilkan kualitas citra seismik lebih akurat dibandingkan melalui pengolahan PSTM.

\subsection{Saran}

Sebaiknya pada tahapan interpretasi diperoleh lebih banyak garis interpretasi horizon pada penampang seismik PSDM, serta melakukan pengolahan yang dilengkapi dengan data sumur.

\section{DAFTAR PUSTAKA}

Bachtiar, A., 2006, Slide Kuliah Geologi Indonesia, Prodi Teknik Geologi, FIKTM-ITB.

Edward, L., E., Nick, J., C., and Jan, D., True Depth Conversion: More Than A Pretty Picture,Scott Pickford, A Core Laboratories Company, Vol.26, No.09.
Fagin, S., 1999, Model-Based Depth Imaging, Course Notes Series, No. 10, Society of Exploration Geophysicists, Tulsa.

Fagin, S., 2000, Model-Based Depth Imaging, Course Notes Series, No. 10, Society of Exploration Geophysicists, Tulsa.

Kosloff, D., Sherwood, J., Koren, Z., Machet, E., dan Falkovitz, Y., 1996, Velocity And Interface Depth Determination By Tomography Of Depth Migrated Gather. Geophysics.

Kosloff, D., 1999, Tomographic Interval Velocity Determination From Prestack Migrated Data. Paradigm Geophysical.

Kusuma, M.I., dan Nafi, A.N., 1986, Prospek Hidrokarbon Formasi Warukin Di Cekungan Barito Kalimantan, Kumpulan Makalah Pertemuan Ilmiah Tahunan XIV IAGI, Jakarta, hal 105-124

Mualimin, Hisan, R.S., Djoko, S.B., Sumahardi, B., 2004,Velocity Model Building Pada Pre Stack Depth Migration; (Pencitraan Pada Struktur Yang Kompleks). Proceding PIT HAGI Ke-29, Yogyakarta

Noble, R., A., Hehu P., dan Charlie Wu, C., H., 1997. Oil Kitchen andPetroleum Bearing Subbasin in Northwest Java Area,IPA Proceedings, 26' Annual Convention, Jakarta.

Van Bemmelen, R.W., 1949, The Geology of Indonesia, Vol.1A, 2nd, Batavia, Netherland, 732 hal. 


\section{LAMPIRAN}

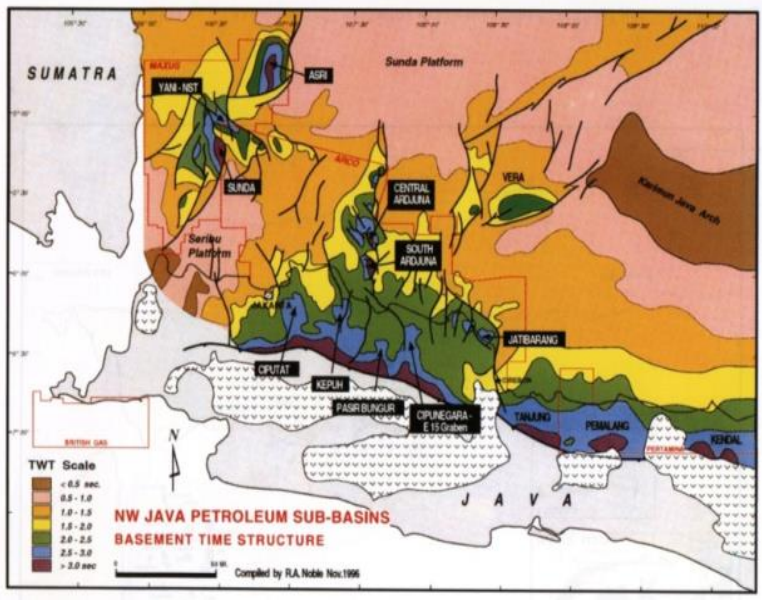

Gambar 1. Cekungan Jawa Barat Utara (Nobel, dkk 1997)

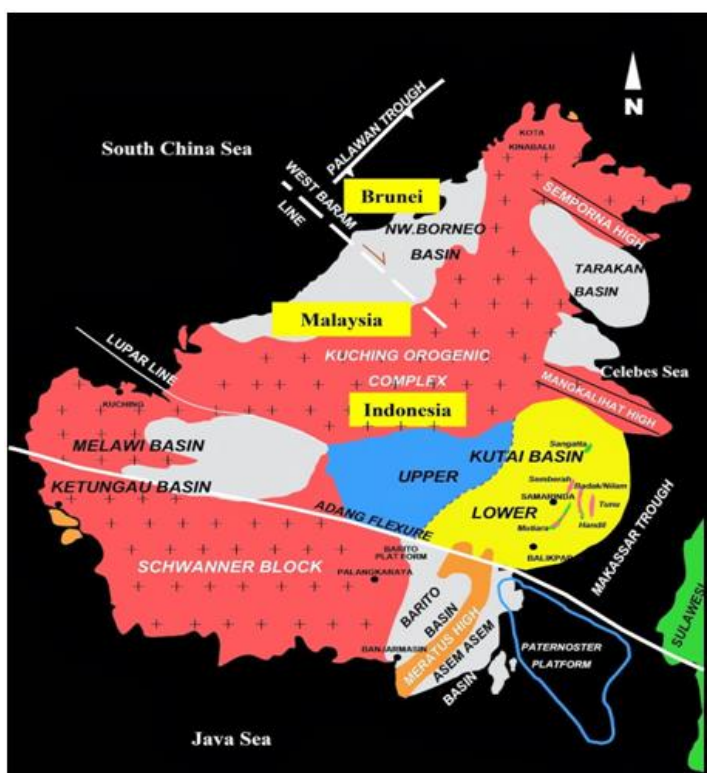

Gambar 2.Kerangkatektonik pulau Kalimantan (Bachtiar, 2006)

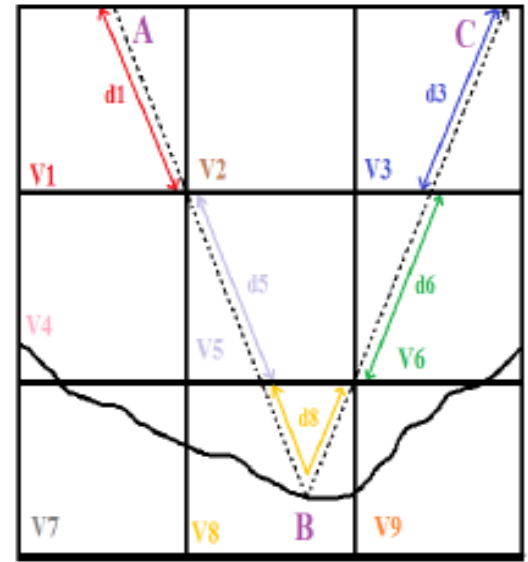

Gambar 3. Model tomografi sederhana (Fagin, 2002)

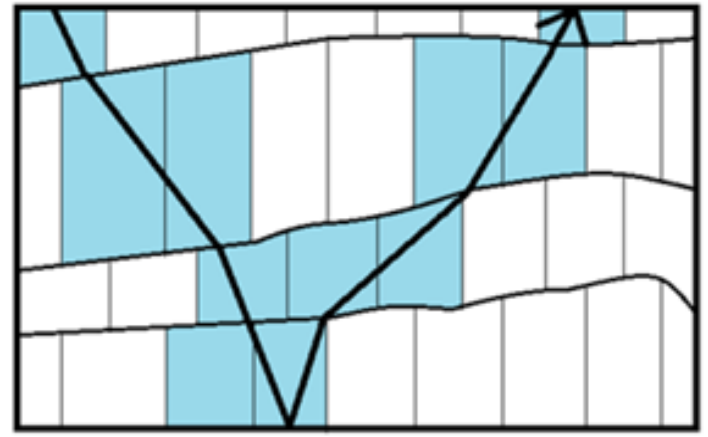

Gambar 4.Horizon Based Tomography (Fagin, 2002)
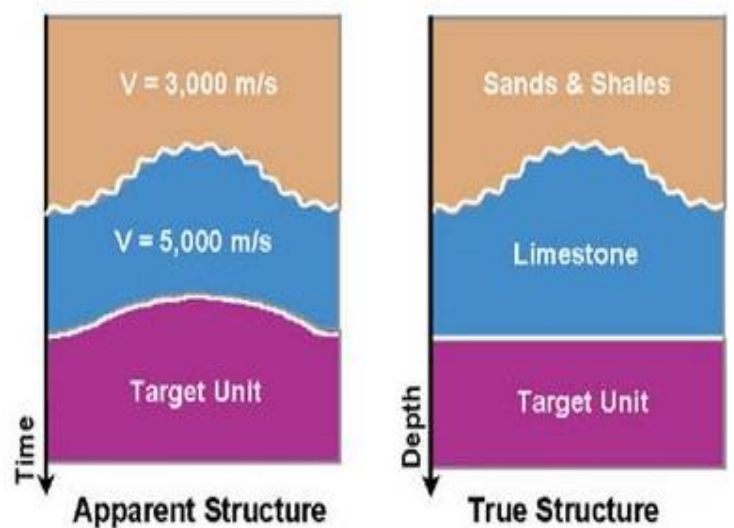

Gambar 5. Ilustrasi efek pull up (Edward dkk, 2002)

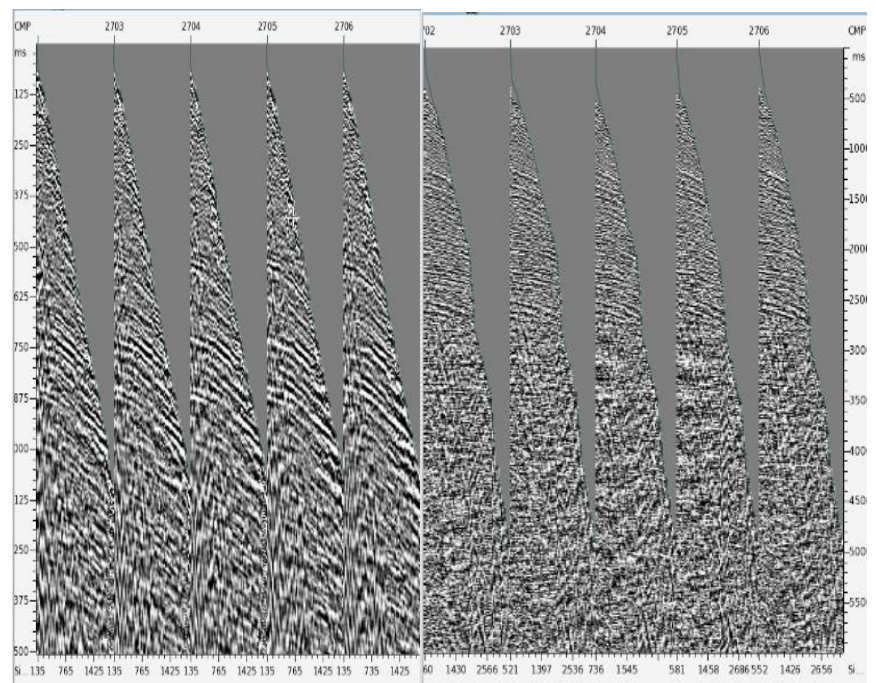

b

Gambar 6. (a) Gather Lapangan A2 dan (b) Gather Lapangan A1 


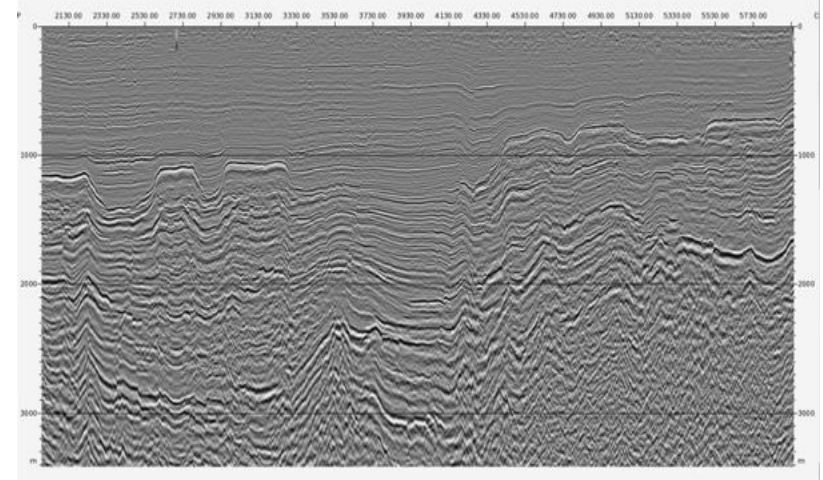

Gambar 7. Migrasi aperture $1951.3 \mathrm{~m}$ lapangan A1

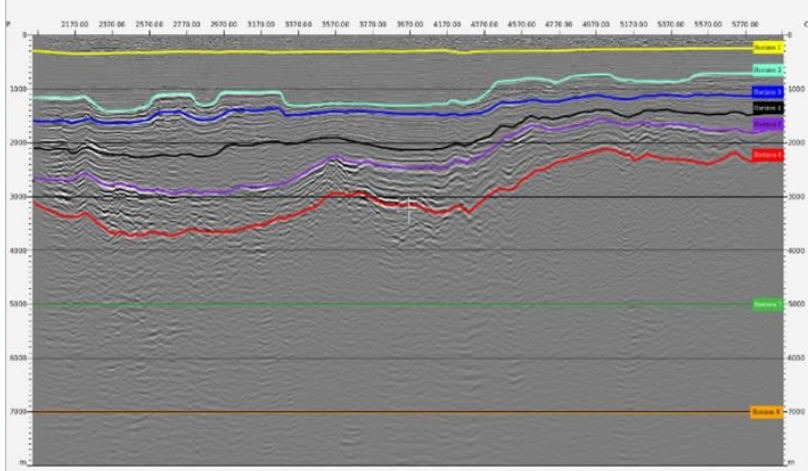

Gambar 9. Interpretasi Horizon Lapangan A1

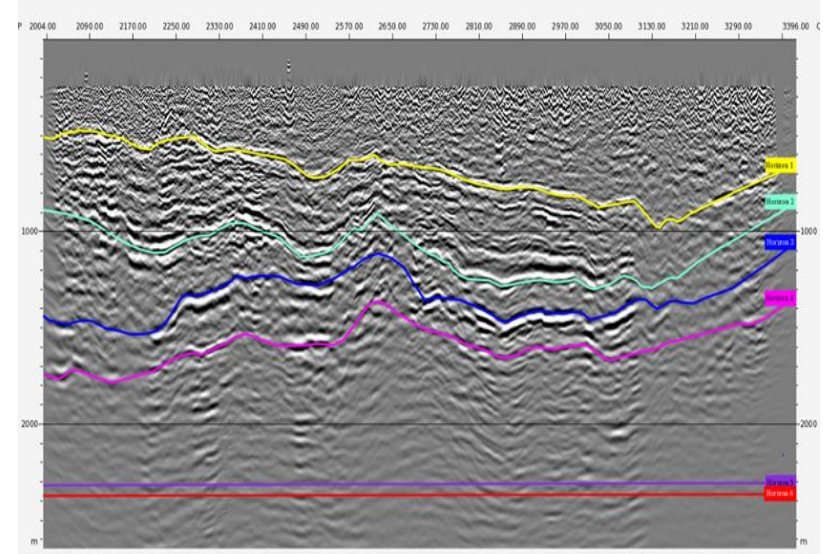

Gambar 10. Interpretasi Horizon Lapangan A2

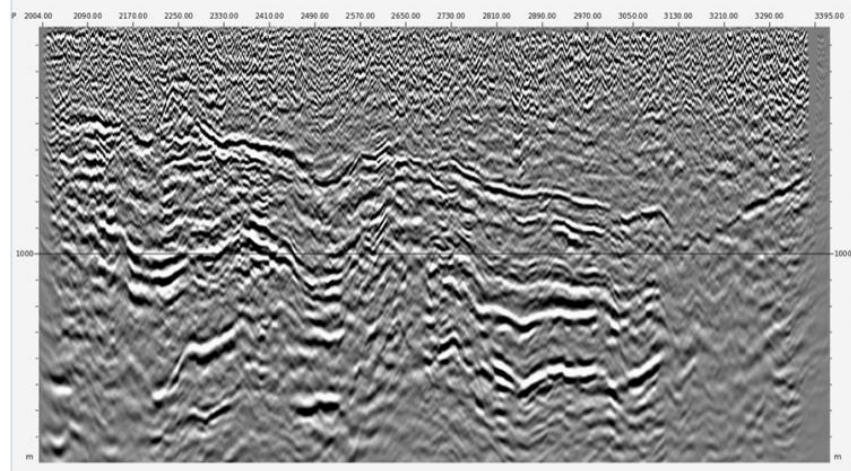

Gambar 8. Migrasi aperture $679.4 \mathrm{~m}$ lapangan A2

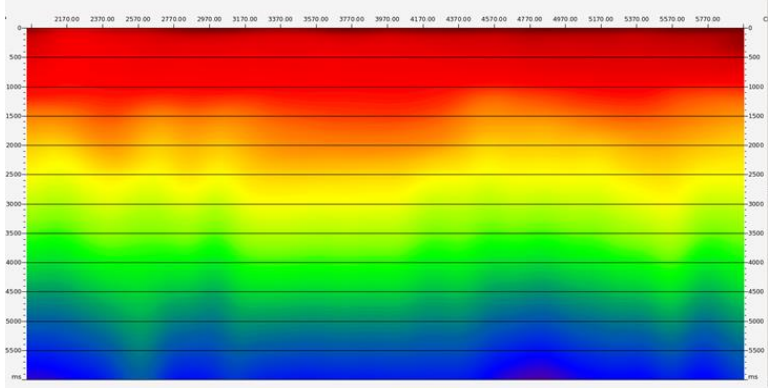

a.

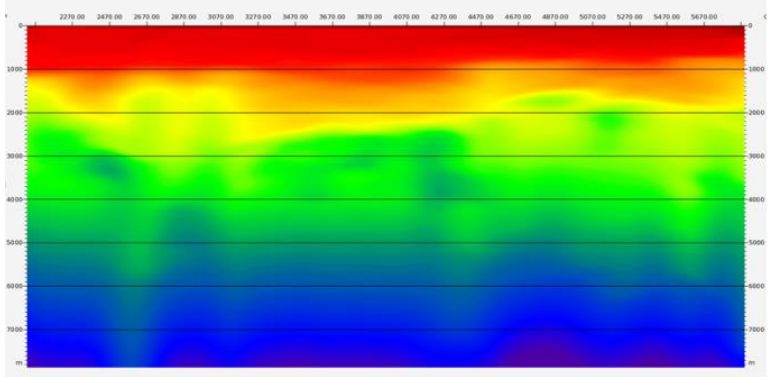

b.

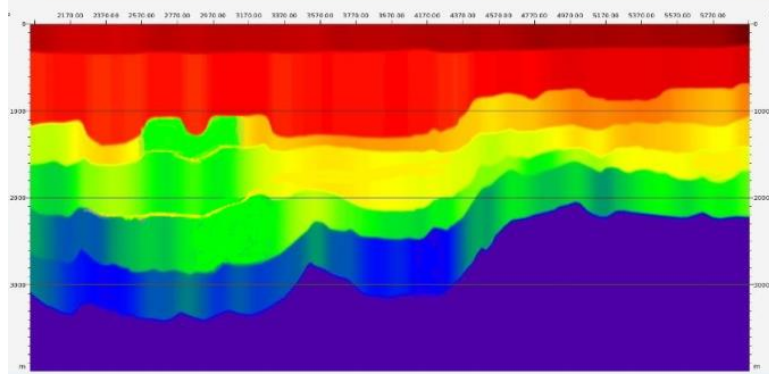

c.

Gambar 11. Model kecepatan lapangan A1 (a) Kecepatan RMS (b) Kecepatan Initial Tomografi(c) Kecepatan final tomografi 


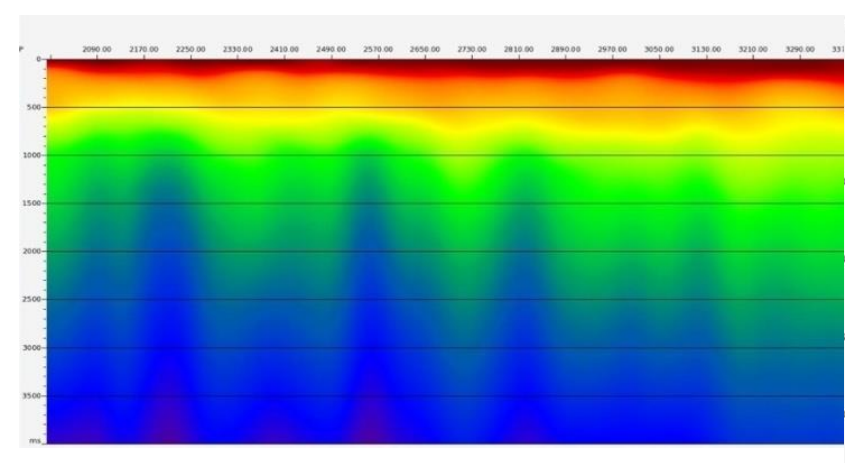

a.

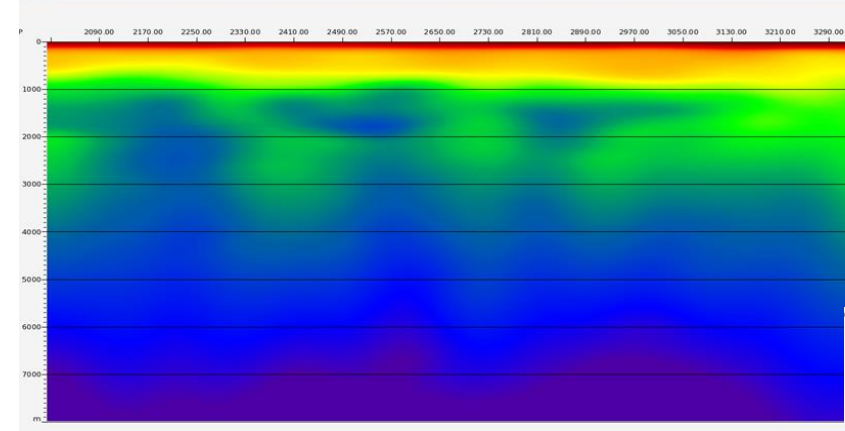

b.

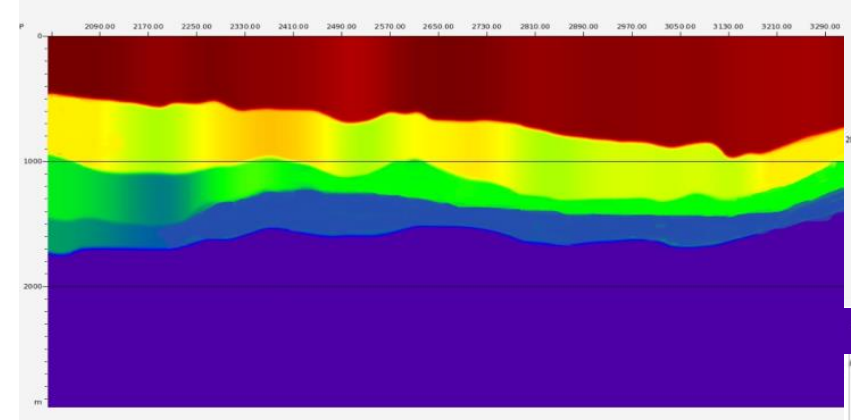

c.

Gambar 12. Model kecepatan lapangan A2 (a) Kecepatan RMS (b) Kecepatan Initial Tomografi(c) Kecepatan final tomografi

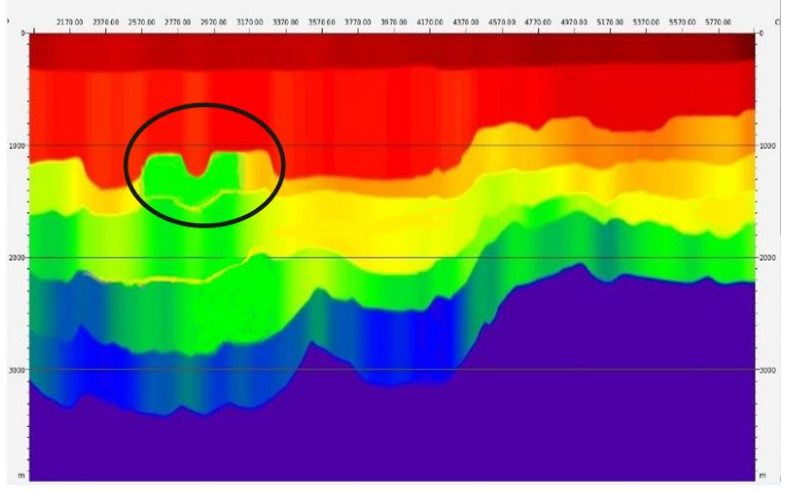

a.

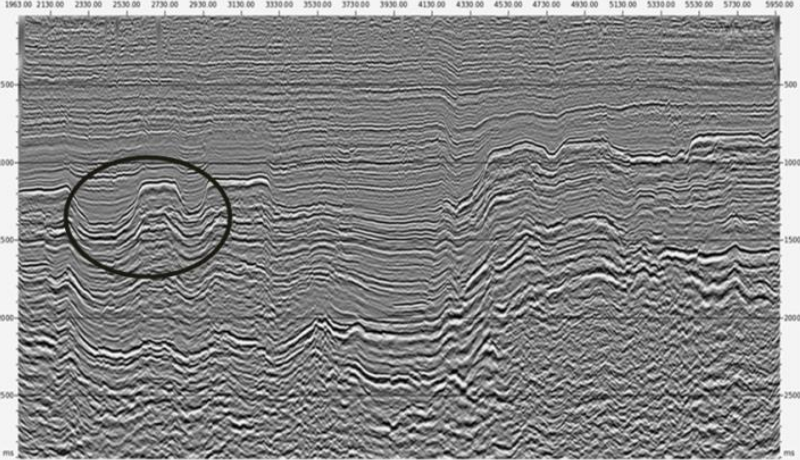

b.

Gambar 13. Perbandingan antara (a) Model kecepatan final dengan (b) PSTM

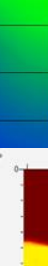

Lapangan A1

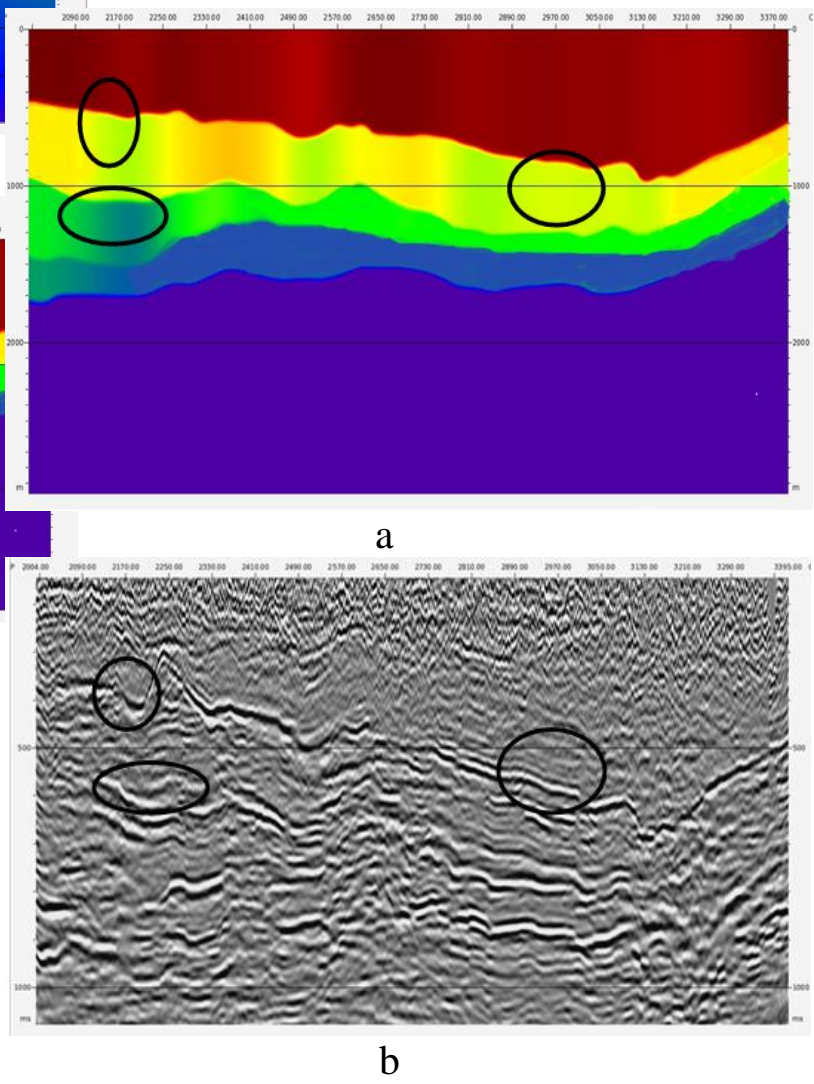

Gambar 14. Perbandingan antara (a) Model kecepatan final dengan (b) PSTM Lapangan A2 


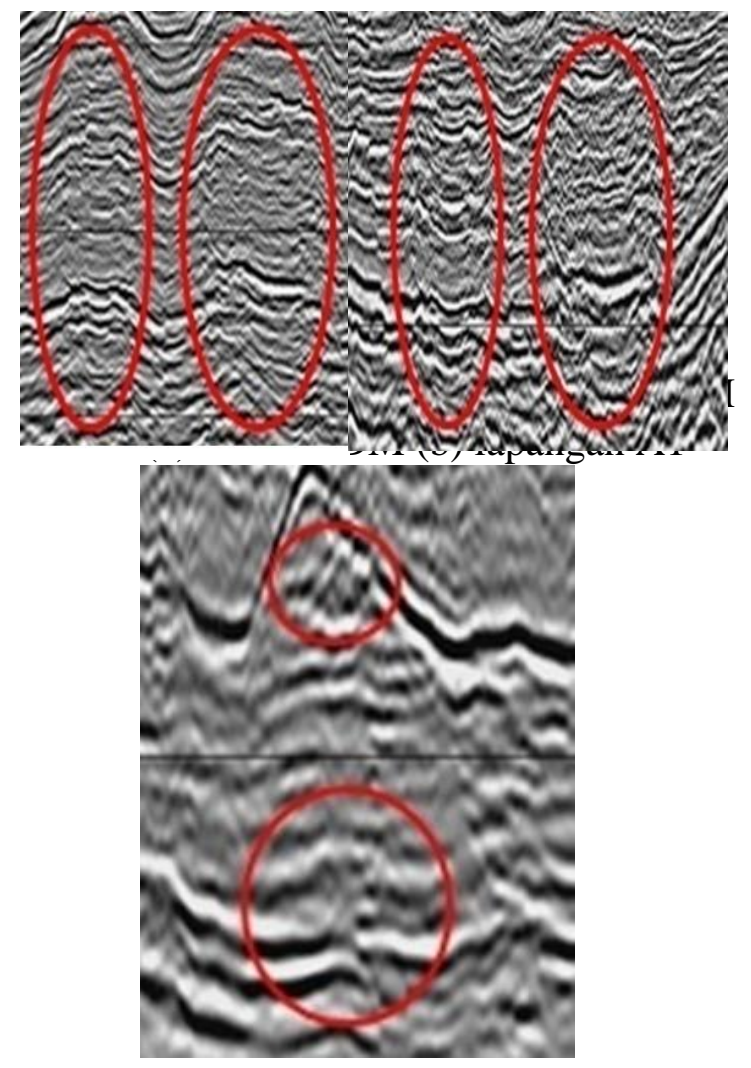

(i)

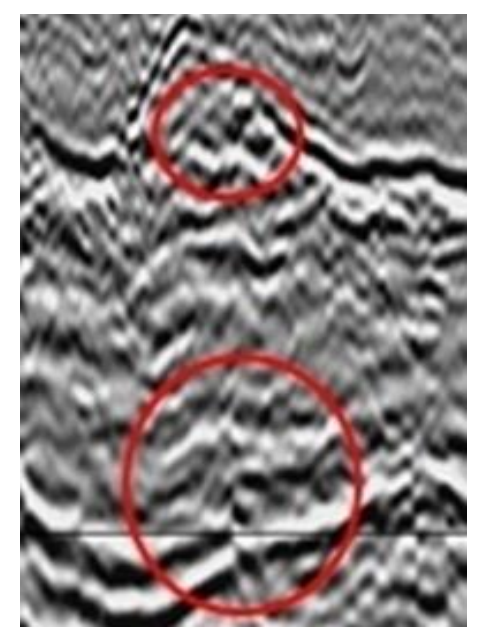

(ii)

a.

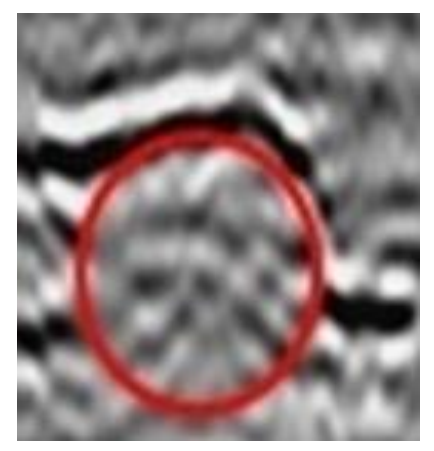

(i)

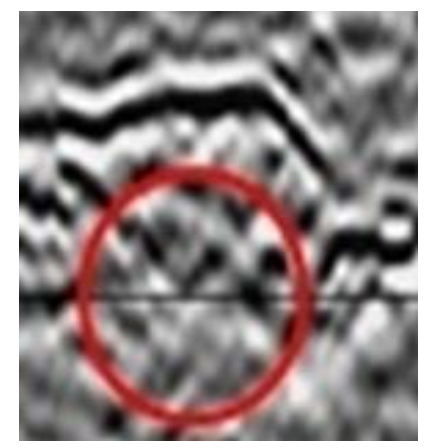

(ii)

b.

Gambar 16. Perbandingan PSTM

a.(i), b (i) dan PSDM a.(ii), b (ii) lapangan A2 